\title{
A VARIANT OF EDM PROCESS (MICROHOLE DRILLING)
}

\author{
P. Chaitanya Krishna Chowdary ${ }^{\# 1}$, A. Ashwini Shanthi ${ }^{\# 2}$, A. Neeraja ${ }^{\# 3}$, N. Nagabhushana Ramesh ${ }^{\# 4}$ \\ \#1,\#2,\#3 Asst. Professor, ${ }^{\# 4}$ Professor \\ \#1, \#2, \#3,\#4 Department of Mechanical Engineering \\ Anurag Group of Institutions, (Formerly C V S R College of Engineering) \\ School of Engineering, Venkatapur (V), Ghatkesar (M), R. R. Dist., Telangana State, India - 500088. \\ ${ }_{\# 1}$ chaitanyamech@cvsr.ac.in, ${ }^{\# 2}$ ashwinimech@cvsr.ac.in \\ \#3 neerajamech@cvsr.ac.in, ${ }^{\# 4}$ drnrameshmech@cvsr.ac.in
}

Abstract-Drilling of holes in EDM is difficult due to spark gap stagnation from erosion debris. This becomes acute in drilling of microholes of large depths. A variant EDM process in such a situation employs water dielectric, pressure flushing and rotating electrode. This study presents some experimental results on the efficacy of the process and the effect of some typical parameters on the erosion rate, accuracy and surface finish.

Keywords-Electrodischarge, Machining, EDM, Microhole, Drilling.

\section{INTRODUCTION}

Electrodischarge machining (EDM) is extensively applied for machining exotic materials and complex shapes. Drilling of microholes (hydro-pneumatic valves, escape holes in dies, start holes for wire cut EDM, nozzles etc.) with large depth to diameter ratio can be machined by laser beam and electron beam machining but their prohibitive costs as well as poor accuracy has led to the development of a variant EDM process with provision for low energy pulses water dielectric and spark gap flushing by pressure flushing through a pipe electrode which is further assisted by Taylor Couette flow of the dielectric from the rotation of the electrode. The set up is illustrated schematically in Fig. 1.

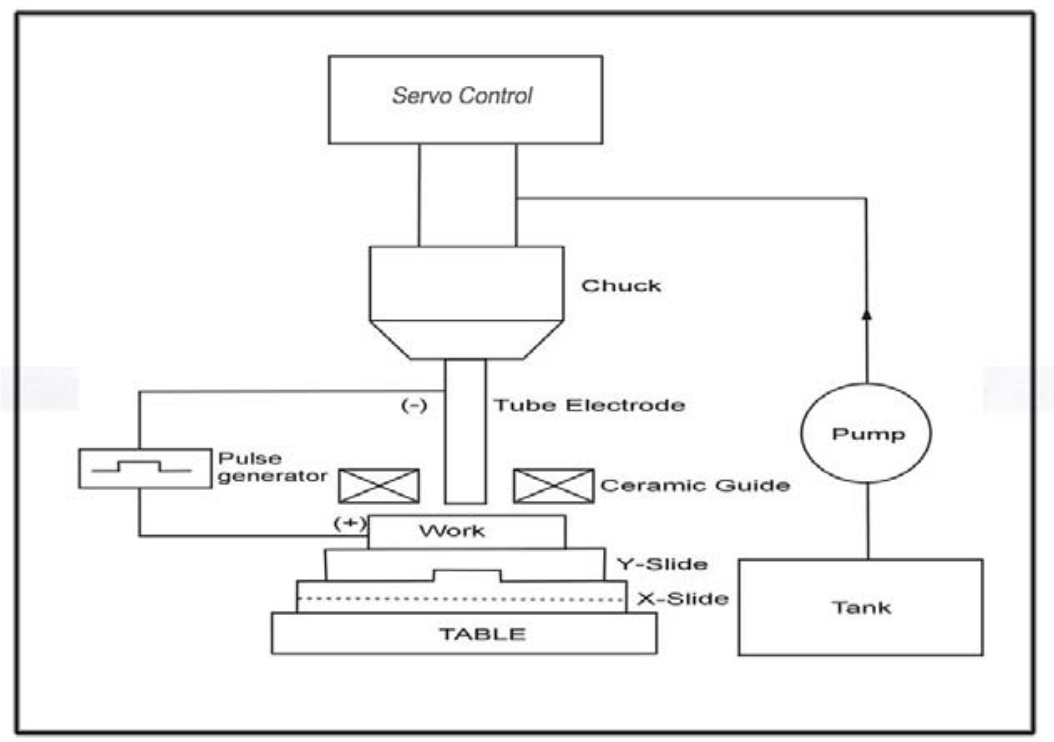

Fig. 1 Schematic Representation of ED Microdrilling

The pipe electrode and work piece form a pair of electrodes with electrode negative polarity with a uniform gap of a few scores of microns. The erosion occurs by high frequency sparks triggered by a square pulse generator. Water dielectric is employed in place of traditional kerosene. Lateral deflection of the slender electrode is prevented by a ceramic guide assembly.

Conventional EDM is difficult for machining small holes owing to frequent short circuits from the spark gap contamination by erosion debris [1]. Poor erosion rates, taper and oversize are typical problems [2].

Efficient use of water as dielectric medium results in smaller spark gaps, fast solidification of eroded particles before they coalesce to form larger size debris [3]. The flushing action is superior due to its low viscosity. 


\section{EXPERIMENT PLAN}

The specimens were prepared on the SPARKONIX Microdrill.

\section{A. Input factors}

Work material: stainless steel, electrode: brass pipes of $1 \mathrm{~mm}$ and $3 \mathrm{~mm}$ diameter pipes with $0.3 \mathrm{~mm}$ diameter holes, pulse current: 3 Amp and 6 Amp, pulse on times: 6 and 10, pulse off times: 4 and 7(dial positions with increasing order) pulse voltage (100V) and flushing pressure (100bar) were kept uniform [4].

B. Output Factors and Their Estimation Mode

Depth dependence of erosion rate: Machining time for drilling different depths. Accuracy: Diameters at the mouth and bottom of holes and the taper, roundness errors on 3D - CMM.

Surface finish: Roughness indices on Talysurf.

\section{III.RESUlTS AND Discussions}

All the results on machining rates, accuracy surface roughness have been compiled and presented in three tables numbered as 1, 2 and 3 for drilling holes of one, two and three mm diameter.

TABLE I: MACHINING DATA FOR DRILLING 1 MM DIAMETER HOLE FLUSHING PRESSURE: 100 BAR

\begin{tabular}{|c|c|c|c|c|c|}
\hline \multicolumn{2}{|c|}{ Depth of Cut (mm) } & $\begin{array}{c}\mathrm{T} \text { on }=10 \\
\mathrm{~T} \text { off }=7 \\
\text { Current }=3 \mathrm{~A}\end{array}$ & $\begin{array}{c}10 \\
7 \\
6 \mathrm{~A}\end{array}$ & $\begin{array}{c}10 \\
4 \\
6 \mathrm{~A} \\
\end{array}$ & $\begin{array}{c}6 \\
4 \\
6 \mathrm{~A} \\
\end{array}$ \\
\hline \multicolumn{2}{|l|}{$0-4$} & 02'-05’' & $01^{\prime}-10^{\prime \prime}$ & $00^{\prime}-45^{\prime \prime}$ & $01^{\prime}-30^{\prime \prime}$ \\
\hline \multicolumn{2}{|l|}{$4-8$} & $03^{\prime}-10^{\prime \prime}$ & $02^{\prime}-25^{\prime \prime}$ & $01^{\prime}-35^{\prime \prime}$ & $03^{\prime}-10^{\prime \prime}$ \\
\hline \multicolumn{2}{|l|}{$8-12$} & $06^{\prime}-40^{\prime \prime}$ & $03^{\prime}-45^{\prime \prime}$ & $02^{\prime}-30^{\prime \prime}$ & $04^{\prime}-50^{\prime \prime}$ \\
\hline \multicolumn{2}{|l|}{ Total time } & $11^{\prime}-55^{\prime \prime}$ & $07^{\prime}-20^{\prime \prime}$ & 04'-50”' & 09'-30” \\
\hline \multicolumn{2}{|l|}{$\mathrm{Ra}(\mu \mathrm{m})$} & 5.6 & 2.4 & 3.4 & 3.8 \\
\hline \multicolumn{2}{|l|}{$\mathrm{Rz}(\mu \mathrm{m})$} & 28 & 16 & 19 & 19 \\
\hline \multirow{3}{*}{$\begin{array}{l}\text { Diameters } \\
\text { of Holes } \\
(\mathrm{mm})\end{array}$} & Top & 1.085 & 1.204 & 1.175 & 1.020 \\
\hline & Bottom & 1.070 & 1.183 & 1.117 & 1.026 \\
\hline & Difference & 0.015 & 0.021 & 0.058 & -0.006 \\
\hline
\end{tabular}

TABLE II: MACHINING DATA FOR DRILLING 2 MM DIAMETER HOLE FLUSHING PRESSURE: 100 BAR

\begin{tabular}{|c|c|c|c|c|c|}
\hline \multicolumn{2}{|c|}{ Hole depth range (mm) } & $\begin{array}{c}\mathrm{T} \text { on }=10 \\
\mathrm{~T} \text { off }=7 \\
\text { Current }=3 \mathrm{~A}\end{array}$ & $\begin{array}{c}10 \\
7 \\
6 \mathrm{~A}\end{array}$ & $\begin{array}{c}10 \\
4 \\
6 \mathrm{~A}\end{array}$ & $\begin{array}{c}6 \\
4 \\
6 \mathrm{~A}\end{array}$ \\
\hline \multicolumn{2}{|l|}{$0-3$} & $01^{\prime}-40^{\prime \prime}$ & $00^{\prime}-40^{\prime \prime}$ & $00^{\prime}-40^{\prime \prime}$ & $00^{\prime}-45^{\prime \prime}$ \\
\hline \multicolumn{2}{|l|}{$3-6$} & 02'-00”' & $00^{\prime}-45^{\prime \prime}$ & $00^{\prime}-45^{\prime \prime}$ & $00^{\prime}-45^{\prime \prime}$ \\
\hline \multicolumn{2}{|l|}{$6-9$} & $02^{\prime}-15^{\prime \prime}$ & $00^{\prime}-50 ”$ & $00^{\prime}-45^{\prime \prime}$ & $00^{\prime}-50 ”$ \\
\hline \multicolumn{2}{|l|}{$9-12$} & $03^{\prime}-40 ”$ & $00^{\prime}-50^{\prime \prime}$ & $00^{\prime}-40^{\prime \prime}$ & $00^{\prime}-50^{\prime \prime}$ \\
\hline \multicolumn{2}{|l|}{ Total time } & $09^{\prime}-25^{\prime \prime}$ & $03^{\prime}-05^{\prime \prime}$ & $02^{\prime}-50 ”$ & $03^{\prime}-10^{\prime \prime}$ \\
\hline \multicolumn{2}{|l|}{$\mathrm{Ra}(\mu \mathrm{m})$} & 5.8 & 2.96 & 3.6 & 3.0 \\
\hline \multicolumn{2}{|l|}{$\mathrm{Rz}(\mu \mathrm{m})$} & 33 & 18.9 & 21.0 & 18 \\
\hline \multirow{3}{*}{$\begin{array}{l}\text { Diameters } \\
\text { of Holes } \\
(\mathrm{mm})\end{array}$} & Top & 2.09 & 2.13 & 2.095 & 2.045 \\
\hline & Bottom & 1.63 & 2.085 & 2.095 & 2.035 \\
\hline & Difference & 0.46 & 0.045 & 0 & 0.01 \\
\hline
\end{tabular}

TABLE III: MACHINING DATA FOR DRILLING 3 MM DIAMETER HOLE FLUSHING PRESSURE: 100 BAR

\begin{tabular}{|c|c|c|c|c|c|}
\hline \multicolumn{2}{|c|}{ Hole depth range (mm) } & $\begin{array}{c}\mathrm{T} \text { on }=10 \\
\mathrm{~T} \text { off }=7 \\
\text { Current }=3 \mathrm{~A}\end{array}$ & $\begin{array}{c}10 \\
7 \\
6 \mathrm{~A}\end{array}$ & $\begin{array}{c}10 \\
4 \\
6 \mathrm{~A}\end{array}$ & $\begin{array}{c}6 \\
4 \\
6 \mathrm{~A}\end{array}$ \\
\hline \multicolumn{2}{|l|}{$0-3$} & 02'-58’' & $01^{\prime}-15^{\prime \prime}$ & $01^{\prime}-10^{\prime \prime}$ & $01^{\prime}-10^{\prime \prime}$ \\
\hline \multicolumn{2}{|l|}{$3-6$} & $03^{\prime}-42^{\prime \prime}$ & $01^{\prime}-23^{\prime \prime}$ & $01^{\prime}-20^{\prime \prime}$ & $01^{\prime}-19 ”$ \\
\hline \multicolumn{2}{|l|}{$6-9$} & $03^{\prime}-56^{\prime \prime}$ & $01^{\prime}-47^{\prime \prime}$ & $01^{\prime}-35^{\prime \prime}$ & $01^{\prime}-29^{\prime \prime}$ \\
\hline \multicolumn{2}{|l|}{$9-12$} & $05^{\prime}-49^{\prime \prime}$ & $02^{\prime}-10^{\prime \prime}$ & $02^{\prime}-15^{\prime \prime}$ & $02^{\prime}-32^{\prime \prime}$ \\
\hline \multicolumn{2}{|l|}{ Total time } & $16^{\prime}-25^{\prime \prime}$ & $06^{\prime}-35^{\prime \prime}$ & 06' - 20”' & $06^{\prime}-30^{\prime \prime}$ \\
\hline \multicolumn{2}{|l|}{$\mathrm{Ra}(\mu \mathrm{m})$} & 6.0 & 2.6 & 3.8 & 5.2 \\
\hline \multicolumn{2}{|l|}{$\mathrm{Rz}(\mu \mathrm{m})$} & 35 & 17 & 18 & 22 \\
\hline \multirow{3}{*}{$\begin{array}{l}\text { Diameters } \\
\text { of Holes } \\
(\mathrm{mm})\end{array}$} & Top & 3.120 & 3.110 & 3.100 & 3.220 \\
\hline & Bottom & 3.115 & 3.135 & 3.075 & 3.08 \\
\hline & Difference & 0.05 & -0.025 & 0.025 & 0.140 \\
\hline
\end{tabular}




\section{A. Depth Dependence of Machining Rate}

The erosion rates are recorded in terms of machining times at different steps of hole depth. For 2 mm and 3 $\mathrm{mm}$ diameter holes the hole depths are selected in steps of 3mm whereas for $1 \mathrm{~mm}$ diameters holes, the steps of 4 $\mathrm{mm}$ were adopted for better accuracy since the machining times were low. In all the cases the erosion rates reduce continuously as indicated by higher machining times for each subsequent step. This is termed as depth dependence of machining rate. But the degeneration in machining rate with increasing depth of hole is not high owing to efficient gap flushing by the pressure flushing and rotating electrode. In conventional EDM there is considerable reduction in machining rates due to poor flushing and debris concentration in spark gap leading to frequent short circuits and stalling of erosion process [5].

Compared to the cases of 2 and $3 \mathrm{~mm}$ diameter holes, the reduction in erosion rates is high in the case of 1 mm diameter holes with increasing depths. The reason is the narrow space around the electrode for the debris to pass through.

\section{B. Effect of Pulse Parameters on Erosion Rates}

The erosion rates are listed in terms of total time required for machining $12 \mathrm{~mm}$ deep hole. As the pulse current increases it is natural to obtain higher machining rates reflected in machining times. Higher pulse current provides higher pulse energy which is responsible for higher erosion rates. The spark power (W) is given by V.I.t.n Joules/sec, where ' $\mathrm{V}$ ' is the average spark voltage, ' $\mathrm{I}$ ' average pulse current, and' $t$ ' is the average effective spark time and ' $n$ ' is the effective frequency of sparks. Any increase or reduction in pulse time setting will result in the corresponding reduction or increase in the frequency of sparking times. To an extent the pulse times do not affect considerably the pulse power at least theoretically. But in practice increase of pulse on time $\left(\mathrm{T}_{\text {on }}\right)$ results in lower machining times for same current and pulse off time $\left(\mathrm{T}_{\text {off }}\right)$. This is found to be so in all cases of machining and is an interesting result. The reason is the corresponding reduction in frequency. The effective pulse time is equal to Ton minus ignition delay $T_{d}$. Ignition delay is the time required for the dielectric breakdown or initiation of spark from the instant the voltage pulse is supplied. Thus the total non-productive pulse time is equal to " $n \times t_{d}$ ". Thus a reduction in pulse frequency leads to a more effective sparking times and improved machining rates.

As a corollary, a reduction in pulse off time which is also a non productive pulse should result in increased machining rates or reducing machining times. But it doesnot occur always. There is random variation. Some times there is an increased erosion rate with lower pulse off time whereas in some other cases the erosion rates reduce with lower pulse off times. If one considers the other implication of pulse off times, in the form of lower deionisation time leading to arcing rather than effective sparking. Similarly higher frequency of sparking creates higher rate of debris generation and in deterioration of flushing process which leads to higher side sparking or remelting of debris by subsequent sparks. Thus reduction in pulse off time can have two possible but contradictory effects. Whichever one is more will lead to correspondingly lower or higher machining rates.

\section{Accuracy of the Machined Holes}

There is a considerable taper in the holes drilled by conventional EDM due to poor flushing, increasing debris concentrations towards the hole mouth and resultant side sparks. This can be offset by an efficient flushing method to clean the spark gap from the eroded debris. It does occur in EDM Microdrilling by forced flushing and rotating electrode and one finds that the taper is very low. Significantly in a few cases, the bottom diameter is more than the mouth diameter of the hole. Clearly it is a case of bend or twist in the pipe electrode which leads to a 'run out' form error. Which in such exceptional cases being more than the taper associated with EDM drilling results in a hole with reverse tape or bottom diameter larger than that at the mouth.

\section{Surface Finish}

The results on surface finish in terms of roughness indices $R_{a}$ and $R_{z}$ are also listed in the three tables. The roughness generally follows the same trend as the erosion rates i.e. higher erosion rates are associated with higher machining rates and typical to the spark erosion process it is random in nature. One can easily understand this feature. Spark energies and correspondingly larger pits or craters which are the characteristic features of the EDM process Is the cause. Naturally the resultant surfaces have a higher roughness. But apart from this qualitative effect it is very difficult to identify any type of quantitative relationship. There is a considerable random variation in the roughness indices with the process parameters. The EDM is by nature a highly random and complex process which is further aggravated in the drilling process. 


\section{IV.CONCLUSIONS}

The following broad conclusions are drawn from this experimental study.

In microhole drilling the high pressure pumping of dielectric through a hollow pipe electrode and its rotation results in a highly efficient flushing action and consequent improvement in machining characteristics. Still there is some depth dependence of machining rates which reduce with increase in hole depth. Higher current and pulse off time lead to improved machining rates but pulse off time has a random effect whereby the machining rates improve or suffer depend on its net effect. There is a form error or taper in drilled holes with higher diameter at the mouth of hole. In some exceptional cases the run out of the rotating electrode from a bend or twist can result in either a straight hole or a tapered hole with lager diameter at bottom. However the roughness indices have considerable variations, random in nature except that qualitatively higher currents lead to higher roughness.

\section{REFERENCES}

[1] Paulo Carlos Kaminski, and Marcelo Neublum Capuano (2003) Microhole machining by conventional electrical discharge machine, Int.Jl.Mach.Tools \& manufacture .43.1143-1149.

[2] Crichton, I.M. and J.A. Mc Geough (1984) Theoretical, experimental and computational aspects of electrical discharge arc machining process, Annals of the CIRP. 33.429-433.

[3] Crichton, I.M. J.A. McGough, W.Munro and C.White, (1981) Comparative studies of ECM, EDM and ECAM, Precision Engg.155159.

[4] Operation manual-Electronica, EDS and EDM systems, 1994.

[5] Masuzawa,T. and C.J. Henvelman. (1994) "A self flushing method with spark erosion machining, Annals of the CIRP. 43.189-192.

\section{AUTHOR PROFILE}

Mrs. Chaitanya Krishna Chowdary Prathi completed her B.Tech and M.S. in Mechanical Engineering from VJIT (JNTUH) and Wichita State University (Wichita, KS) in 2006 and 2009 respectively.

Ms. Ashwini Shanthi A. completed her B.Tech in Mechanical Engineering from SRTIST (JNTUH) and M.Tech in CAD/CAM from BRIG (JNTUH) in 2006 and 2014, respectively.

Mrs. Neeraja A. completed her B.Tech in Mechanical Engineering from JNTUH and M.Tech in AMS from PRRM in 2000 and 2012 respectively.

Dr. Nagabhushana Ramesh N. completed his B.E in Mechanical Engineering (1986) and M.E in Production Engineering from Osmania University, Hyderabad, A.P, India, (1994) Ph.D in Mechanical Engineering with specialization as Production Engineering in the field of Electro Discharge Sawing (Electro Discharge Machining) from Osmania University, Hyderabad, A.P, India (2007). TOTAL EXPERIENCE 28, Papers Published in International Journals: 09 No's National Journals: 01 No's, International Conferences: 20 No's, National Conferences: 13 No’s, Guided for Ph.D awarded:02 No's, Presently Guiding for the Ph.D:01 No's. 